\title{
Domesticating Computers and the Internet
}

\author{
Jonathon N. Cummings \\ Carnegie Mellon University \\ Human-Computer Interaction Institute \\ Pittsburgh, PA 15213 U.S.A \\ +14122682869 \\ jnc@andrew.cmu.edu \\ Robert Kraut* \\ Carnegie Mellon University \\ Human-Computer Interaction Institute \\ Pittsburgh, PA 15232 U.S.A \\ +14122687694 \\ Robert.Kraut@cmu.edu
}

\author{
May 4, 2001 \\ In press, The Information Society \\ * Send all correspondence to Robert Kraut
}




\section{Abstract}

The people who use computers and the ways they use them have changed substantially over the past 25 years. In the beginning highly educated men in technical professions used computers for work, but over time a much broader range of people are using computers for personal and domestic purposes. This trend is still continuing, and over a shorter time scale has been replicated with the use of the Internet. This paper uses data from four national surveys to document how personal computers and the Internet have become increasingly domesticated since 1995 and to explore the mechanisms for this shift. Now people logon more often from home than from places of employment and do so for pleasure and for personal purposes rather than for their jobs. Analyses comparing veteran Internet users to novices in 1998 and 2000 and analyses comparing the change in use within a single sample between 1995 and 1996 support two complementary explanations for how these technologies have become domesticated. Women, children and less well-educated individuals are increasingly using computers and the Internet and have a more personal set of motives than well-educated men. In addition, the widespread diffusion of the PC and the Internet and the response of the computing industry to the diversity in consumers has led to a rich set of personal and domestic services.

Keywords - Internet use, personal computers, domestication, national survey, demographics, online behavior, communication, information

\section{Acknowledgements}

Mark Fichman, Sara Kiesler, and Jennifer Lerner provided helpful comments on a previous draft of this paper. We also thank the Pew Research Center For The People and The Press and The Pew Internet and American Life Project for providing the national survey data. These organizations bear no responsibility for the interpretations presented or conclusions reached based on our analyses of the data. 
Domesticating computers and the Internet

Introduction

The invention of the ARPAnet in 1969 rapidly led to new ways of working in science and industry. This national computer network allowed scientists to share computing resources across space and time, giving researchers in government, industry, and academia access to remote computers. Researchers at Xerox's Palo Alto Research Center were among the inventors of the modern personal computer. It was introduced to a broader market with the Apple and IBM personal computers in the early 1980s. It was not long before people began bringing these computers home to connect to national networks, primarily for work-related purposes (Vitalari, Venkatesh, \& Gronhaug, 1985). Users of home computing and networks during this period tended to be highly educated young and middle-aged men (Frenkel, 1990; Klawe \& Leveson, 1995). Some used their technology to telecommute instead of going to the office while others used it for work after coming home (Kraut, 1989).

It was not until twenty-five years after the birth of the Internet that both scholarly writing and the popular press started documenting the increase in household Internet use for purposes other than work (Anderson, Bikson, Law, \& Mitchell, 1998; Kraut, 1996; Times Mirror Center for the People and the Press, 1994; U.S. Department of Commerce, 1999). For example, Bikson, Law, and Mitchell (1996) highlighted increases in the use of Internet from home to send and receive electronic mail. Similarly, a Commerce Department report documented the increase in household Internet availability, from $18.6 \%$ of all U.S. households in 1997 to 26.2\% in 1998 (U.S. Department of Commerce, 1999). Other more recent surveys (e.g., Pew Internet and American Life Project, 2001) estimate that almost 70\% of US adults now have Internet access.

The thesis of the current article is that the late 1990s have been characterized by the domestication of the Internet. By domestication, we mean a shift from using personal computers and the 
Internet in a work setting primarily for income-producing activities to using them in more domestic settings, for more personal and household purposes. We use the term "domestication" in a more literal sense than authors such as Silverstone and Haddon (1996), who focus on the political and cultural underpinnings of communication and information technologies in the home. In this paper, we re-analyze data from several recent surveys of the U.S. population about its use of computers and the Internet. Using this data, we document shifts in both location and purpose of computing and Internet use, confirming trends that have been observed in the popular press. The data show both the anticipated increase in use of technology for domestic purposes and a more surprising decline in its use for workrelated purposes.

We use the survey data to explore two complementary mechanisms through which domestication is occurring — a shifting population and a shifting environment. These mechanisms are general ones, characteristics of the evolution of many innovations, not merely personal computers and the Internet. The first of these mechanisms reflects shifts in attributes of a user base as an innovation becomes more popular. The types of people who adopt an innovation early in its history differ systematically from later adopters (Rogers, 1995). Because early technology tends to be more costly and less valuable than later technology, early adopters frequently must have stronger needs for using it compared to later adopters to put up with the costs and quality of service. Often these strong needs are economic, as in the case of the early telephone, where the early adopters were frequently managers who had economic needs for communication (Aronson, 1977). Later adopters applied this technology to personal, non-economic purposes, as it became cheaper and more reliable (Aronson, 1977). In the case of the personal computer and the Internet, a shift in the user base might be associated with shifts in their motives. If so, we would expect that later users would use computing technology less heavily than earlier ones and that their uses would be less focused on the economically important domain of work and more on the personal. 
We test the "shifting population" mechanism in two ways. First, through comparisons of data collected in 1995, 1998, and 2000, we document that the Internet-using population has grown more heterogeneous over time and more similar to the US population as a whole. However, controlling for shifts in demographic characteristics does not account for shifts in use. Second, using data from 1998 and 2000, we show that in contrast to Internet veterans, who have been online for over a year, Internet novices (i.e., those having only recently gotten online) are lighter and more domestic users.

The "shifting environment" explanation recognizes that innovations and the environments in which they operate change as they diffuse and are used. The user base, the technology, and the uses to which it are put are interdependent. Merely having more people online changes the ways the Internet can be used, for example, by making interpersonal communication a more valuable activity. In addition, the computer industry itself responds to changes in the user base and their motives by making new services available, which, in turn, enables new uses. For example, instant messaging services and "buddy lists" make the Internet more attractive for interpersonal communication, and high-speed networks make it more appropriate for transporting bandwidth-hungry entertainment applications, like music. Improvements in computers and the Internet make them more suited for some personal applications, for example, as increasingly faster processors and networks make the technology more suitable for graphics-filled games or large music files like MP3s.

Finally, as a community of users appropriates an innovation, they develop and communicate norms about acceptable use, which can influence the behavior of their peers and subsequent generations. These norms can be communicated directly, through personal influence (e.g., Kraut et al., 1998) or, indirectly, though the mass media. For example, comments among friends about "emailing" each other and references to electronic mail in news articles, popular movies, and cartoons can change people's perception of the utility and social desirability of using the Internet for interpersonal communication. 
We test the shifting environment explanation by examining how a single sample used the Internet first in 1995 and then subsequently in 1996. Because the user base remained constant in this analysis, changes in how they used computing and the Internet can plausibly be attributed to changes in unmeasured environmental factors, such as the services available online and the zeitgeist surrounding Internet use.

\section{Current Trends}

In this section, we describe several trends in computing and Internet use, re-analyzing data originally collected by the Pew Research Center for The People and The Press, and the Pew Internet and American Life Project. Our results extend research reported elsewhere (e.g., Clemente, 1998; U.S. Department of Commerce, 1999). In particular, through our analysis, we document that in the period between 1995 and 2000, use of computers and the Internet shifts from places of employment to home, from economic to more pleasurable purposes, and from work interests to more personal ones.

The data come from three national probability samples of the U. S. population (i.e., telephone numbers randomly selected from residential telephone exchanges), conducted in 1995 (N=4005), 1998 $(\mathrm{N}=2000)$, and $2000(\mathrm{~N}=3533)$. We note in the results below which questions were asked for each time periods. The data include measures of where people used personal computers and the Internet, and the purposes for which they used them. In 1996, as part of another survey, the Pew Research Center reinterviewed 194 individuals from the 1995 survey who reported sometimes going online at that time.

By comparing random samples of the U.S. population at three times, we examine how the demography of the user base and uses of computing technology have changed from 1995 to 2000. This research logic is based on an assumption that sampling and research methods were constant across the time periods. A single survey research firm — Princeton Survey Research Associates_ conducted all of the surveys. Because they used the same sampling and interview techniques in the different time 
periods, differences in research methods cannot account for differences in results over time. ${ }^{i} \mathrm{We}$ compare only questions that were asked identically; however, not all of the questions were asked in 2000, and so our comparisons exclude 2000 for many items.

There have been debates in the methodological literatures about the accuracy of self-reports of behavior (e.g., Bernard, Killworth, \& Sailer, 1980; Freeman, Romney, \& Freeman, 1987; Stone, Turkkan, Cachrach, Jobe, Kurtzman, \& Cain. 2000). The national surveys employed two effective methods for eliciting estimates. The first method asks respondents for general estimates about the frequency of a behavior (e.g., "How often do you go online to ..."). In answering these questions, respondents are judging their behavior relative to a comparison group, rather than calculating an absolute value. The second method asks respondents to report their behavior on a particular day (e.g., “Did you go online yesterday to ..."). This technique is less susceptible to problems of recall and interpretation, but is susceptible to problems of sampling. Regardless of the absolute accuracy of these self-report measures, there is little reason to believe that their accuracy changed between 1995 and 2000. $\underline{\text { Time Trends in Locations of Use. }}$

Table 2 shows the percent of those who used a personal computer and the Internet from work and home in the 1995, 1998, and 2000 surveys, and the intensity with which they did so. Questions about computer use were not asked in 2000. Between 1995 and 1998, there were both declines in the percentage of computer users using computers from work and increases in those using it from home. Between 1995 and 1998, more people reported ever using a computer at home (66\% vs. 69\%), more reported using a computer at home yesterday (18\% vs. $20 \%)$, and they reported using it at home more days a month (8.8 vs. 10.7). However, intensity of use declined over this period, in terms of time the computer was used in a particular day (93 minutes vs. 84 minutes). This pattern of results is consistent 
with the hypothesis that people who acquire new technology later in its diffusion cycle have less strong needs for it and therefore use it less. We examine this hypothesis in more detail below.

Insert Table 2 about here

From 1995 to 2000, the percentage of the U.S. population who went online in a particular day more than tripled, from $8 \%$ in 1995 to $29 \%$ in 2000 . In all three years, adults were more likely to go online from home than from work, but this gap increased over time, from a difference of $23 \%$ in 1995 to a difference of $35 \%$ in $2000\left(\underline{F}_{\text {linear }}=5.17, \underline{p}<.05\right)$. While the increase in use of the Internet from home over time was not significant, the decline in use of the Internet from work was significant (for linear trend, $\underline{\mathrm{t}}=-2.27, \underline{\mathrm{p}}<.05)$.

$\underline{\text { Time Trends in Motives for Use }}$

Table 3 shows reasons for which people reported using a personal computer at home and for going online in the 1995, 1998, and 2000 surveys. Only questions about use of electronic mail were asked identically in all three time periods, so most of our discussion with contrast the 1995 and 1998 surveys. For both computing and Internet use, the relative importance of personal rather than work motives increased. For example, in both 1995 and 1998, people reporting using their home computer more for personal purposes than for their jobs, and this gap increased with time (for the interaction, $\underline{\mathrm{t}}=$ $3.28, \mathrm{p}<.01)$. Looking at trends in Internet use, work-related activities were more important than pleasurable ones in 1995, but this pattern had reversed by 1998 (for the interaction, $\underline{\mathrm{t}}=8.45, \underline{\mathrm{p}}<.001$ ). As was the case with location of use, this shift was a result both of an increase in pleasurable motives and a decline in work-related ones. The use of the Internet to access all sorts of information increased 
between 1995 and 1998, but increases for getting information about hobbies and entertainment, travel, and finance_-all personal motives_-were especially large.

Insert Table 3 about here

From 1995 to 2000, the population virtually doubled its use of the Internet to communicate with friends and family, from $42 \%$ of respondents to $82 \%$. During this period, use of electronic mail for work-related purposes was steady at about $51 \%$ of the population, while use of electronic mail for personal purposes grew from $50 \%$ of the population to $82 \%$ (for the interaction, $\underline{\mathrm{t}}=12.55, \underline{\mathrm{p}}<.001$ ). $\underline{\text { Summary of the recent trends in personal computing and Internet use }}$

In summary, during this five-year period, more people were using computers and the Internet from home and were increasingly using them for personal and pleasurable purposes, rather than for economically instrumental ones. Personal and pleasurable uses increased at the same time that instrumental, work-related uses were either stable or declined. Although a larger proportion of the populations was using computer-based technology, they were using it less intensively. During this period, computing increasingly became an optional, domestic technology like the residential telephone, television, or stereo, rather than an obligatory workplace tool, which has a direct economic impact on its user.

\section{Domestication of the Internet: Who or what?}

Previously we identified two main reasons why computing and Internet use could have shifted toward the home and toward more personal and enjoyable motives. The first is that a more diverse population of personal computer and Internet users brought with it a different set of needs and preferences than those held by earlier generations of users. If the Internet were becoming more 
domesticated because of changes in the user base, then one would expect two patterns in the data. First, the demographic profile of Internet users should have changed in the recent past, and that statistically controlling for these demographic differences should account for some of the changes in computing and Internet use observed between 1995 and 2000. Second, in any given year, people who have only recently moved online (novices) will use it for more domestic purposes than those who have used the Internet for a longer time (veterans).

A second explanation is that changes in services available online and the cultural environment in which they exist account for the shifts in usage patterns, rather than changes in the demographic profile of users. If this explanation were true, we would expect to see that the same people at different times would be using computers and the Internet differently. In particular, in more recent times they should be more likely to connect to the Internet from home and to report using computing technologies for pleasure and for personal purposes rather than for work-related ones.

\section{Method}

We conducted three sets of analyses. The first compared domestication trends in 1995, 1998, and 2000 controlling for the demographic differences in the user population between these two periods. The second used the 1998 and 2000 surveys to contrast veteran Internet users, who had been online for two years or more ( $\underline{n}=431$ for 1998 and $\underline{n}=1050$ for 2000$)$ with novice users, who had been online for one year or less ( $\underline{n}=353$ for 1998 and $\underline{n}=635$ for 2000 ). By comparing different people at a single time period, this analysis holds constant changes in the Internet itself and its surrounding environment, focusing on differences in user characteristics. The third analysis is longitudinal, comparing responses from 1995 and 1996 from a single sample. The longitudinal analysis, by comparing the same people at two time periods, holds constant changes in users' characteristics, to examine changes in what they are doing over time. 


\section{Results}

Comparing 1995 to 1998 , controlling for demographics.

As personal computing and the Internet have diffused, the user population has become more similar to the U. S. population as a whole (U.S. Department of Commerce, 1999). Comparisons of 1995, 1998, and 2000 Internet users, for example, show that in the later period, users were more likely to be female $\left(38 \%\right.$ female in 1995 vs. $49 \%$ female in $\left.2000 ; \underline{F}_{\text {linear }}=31.5, p<.001\right)$, older $(65 \%>30$ yrs in 1995 vs. $69 \%>30$ yrs in $\left.2000 ; \underline{F}_{\text {linear }}=4.21, \mathrm{p}<.05\right)$, and less well educated $(46 \%<$ college degree in 1995 vs. $60 \%<$ college degree in $\left.2000 ; \underline{\mathrm{F}}_{\text {linear }}=44.8, \mathrm{p}<.001\right)$. Even though there remain gender, age, education differences between Internet users and non-users, the demographics of Internet users are certainly becoming more diverse. However, the gap between users and non-users in minority status and income has not declined as much as the gaps in gender, age, and education (Hoffman \& Novak, 1997). Comparisons of 1995, 1998, and 2000 Internet users show no significant changes in the proportion of Internet users who are White (84\% White in 1995 vs. 83\% White in $\left.2000 ; \underline{F}_{\text {linear }}=.031, \mathrm{p}>.10\right)$ and with incomes over $\$ 40,000\left(63 \%\right.$ in 1995 vs. $64 \%$ in $\left.2000 ; \underline{F}_{\text {linear }}=.035, \mathrm{p}>.10\right)$.

The analyses in Table 4 test whether controlling for the demographic attributes of the user base can account for the increased domestication of computers and the Internet. Dependent variables in Table 4 have been coded so that a higher number represents more domestication (i.e., greater relative use of the Internet from home rather than from work and greater use for personal and pleasurable purposes rather than work-related ones). The analyses show different types of people do use the Internet from different locations and for different purposes, but that these effects are relatively weak and controlling for them does not account for the shift in location of use and types of uses seen between 1995 and 2000.

Insert Table 4 about here 
For example, even though more women and older people were using the Internet in 1998 and 2000 than in 1995, they were less likely than men and younger people, respectively, to go online from home. Controlling for demographic differences in the user base between 1995 and 2000 does not reduce the shift in location, i.e., using the Internet from home rather than work, during this period ( $\underline{\text { Beta }} 1995$ through $2000=.141$ without control and .144 with control). Similarly, controlling for demographic shifts does not reduce the increasing trend of using a home computer for personal instead of work purposes, to go online for pleasure rather than for work, and to use electronic mail for personal rather than work purposes.

Comparing veterans and novices in 1998 and 2000.

The previous analyses controlled only for a few demographic characteristics; other, nondemographic differences between early users and later ones may account for the increasing domestication of computing. A more direct test of the proposition that shifts in the user base accounted for increases in domestication compares more and less experienced Internet users during a single time period. By examining a single time period, this comparison holds constant both the availability of particular services online and the zeitgeist surrounding their use. Both the 1998 and 2000 surveys asked respondents "When did you first start going online?" Based on a median split, we defined novices as those who reported first going online within the last six months or year and veterans as those who had been online two years or more. The demographic differences between veteran and novice users in 1998 and 2000 were similar to the demographics shifts in the general population of users between 1995 and 2000 reported earlier. As shown in Table 5, compared to veteran users, novices in both years are more likely to be women, older, and less well educated. Veterans and novices did not differ on minority status in both years, and on income in 1998, though veterans were wealthier than novices in 2000. 
Insert Table 5 about here

Across a number of measures, novices used computers and the Internet less heavily than veterans. They were less likely to use a computer from home, less likely to use a home computer for work, and less likely to use the Internet for a variety of purposes. Turning to the issue of domestication, the data is mixed but in general suggest that novices were more likely to use computers and the Internet at home and for personal reasons. In particular, novices were more likely to use the Internet at home and less likely to use it from work than veterans, though the difference was statistically significant only for 2000 (for the 1998 interaction, $\underline{\mathrm{t}}=1.53, \underline{\mathrm{p}}=.13$; for the 2000 interaction, $\underline{\mathrm{t}}=2.58, \underline{\mathrm{p}}<.05$ ). Both novices and veterans were more likely to use their home computer for personal rather than work-related purposes, but the difference was significantly greater for novices than for veterans (for the 1998 interaction, $\underline{t}=2.20, \underline{p}<.05)$. In addition, although they were a little less likely to go online for pleasure than veterans, they were substantially less likely to use it for work-related purposes (for the 1998 interaction, $\underline{\mathrm{t}}=2.61, \mathrm{p}<.01)$. Both novices and veterans were more likely to use email for personal than for work-related purposes, but the difference was larger for novices, at least in 2000 (for the 1998 interaction, $\underline{\mathrm{t}}=.16, \underline{\mathrm{p}}>.20$; for the 2000 interaction, $\underline{\mathrm{t}}=3.51, \underline{\mathrm{p}}<.001)$.

Table 6 shows differences in how novices and veterans use the Internet in 1998 to collect information. Respondents overall were more likely to use the Internet to look for information about their work or job than they were to engage in a variety of personal and family-related activities. Again, across all measures, in terms of gathering information, novices are lighter users of the Internet than veterans.

Insert Table 6 about here 
Across of number of questions, however, novices had relatively more domestic and personal uses of the Internet than the veterans. For example, they used the Internet in 1998 for work-related research approximately half as frequently as the veterans (54\%), but used it for getting travel information at approximately the same rate as veterans $(98 \%$, for the interaction, $\underline{\mathrm{t}}=4.96, \underline{\mathrm{p}}=.001$.) Similarly, they used it at approximately the same rate as veterans for paying bills $(85 \%$, for the interaction, $\underline{t}=.041, \underline{p}>$ $.20)$, for getting entertainment and hobby information $(79 \%$, for the interaction, $\underline{t}=2.07, \underline{p}<.05)$, for getting news $(67 \%$, for the interaction, $\underline{\mathrm{t}}=3.74, \underline{\mathrm{p}}<.001)$, and for getting financial information $(66 \%$, for the interaction, $\underline{t}=3.25, \underline{p}<.001$ ). That is, although novices use the Internet less than veterans for getting information of all sorts, the differences are smaller when the information is for personal and domestic uses rather than for paid employment.

Comparing the same people across time.

Table 7 compares the behavior of the sub-sample of respondents initially interviewed in 1995 who were subsequently re-interviewed in 1996. It includes all the questions from Table 3 that were asked in 1995 and repeated in 1996. We use this comparison to indirectly assess the extent to which changes in the services available online and changes in the normative environment during this interval may have caused an increase in domestication. This is a weak inference, based on reasoning that when the same individuals shift behavior over time, some (unmeasured) changes in the environment are potentially causing these behavioral shifts.

Insert Table 7 about here 
The six repeated questions allow us to examine only three aspects of domestication between 1995 and 1996: using a computer from home versus work, using the Internet from home versus work, and using the Internet for pleasure versus work. Although the trends were consistent with the prediction that the same individuals treating computing more domestically in 1996 than in 1995, none of the 1995/1996 interactions reached statistical significance. In 1996 the sub-sample was a little more likely to use the Internet from home and a little less likely to use it at work (for the interaction, $\underline{t}=-.92, p=.36$ ). In addition, although the sub-sample was more likely to use the Internet for work than for pleasurable purposes in both years, use for pleasure increased faster than use for work, so that by 1996 the Internet was being used for pleasure almost as much as it was for work (for the interaction, $\underline{t}=1.42, \underline{p}=.16$ ).

\section{Discussion}

Overall, the results document that computing and Internet use have become increasingly domestic and personal since 1995. In contrast to the earlier period, in 1998 and 2000 people were more likely to use computers and the Internet from home and to use them for personal and pleasurable purposes, rather than for their paid employment. This trend applies to the use of a home computer, to the use of the Internet, to the use of the World Wide Web to get information for hobbies, entertainment, travel, and household chores rather than for work, and to the use of email to contact friends and family.

There are two complementary explanations for these shifts in use. First, people who were late arrivals to the world of personal computing and the Internet brought with them a different set of motives and customary uses than those who had a longer history online. These late arrivals were lighter users of personal computers and the Internet on many measures, and their uses were different in kind as well. The analyses contrasting novices with veteran Internet users in 1998 and 2000 show that the novices were relatively more likely to use computing at home, to use their home computer for pleasure rather 
than for work, and were more likely to get personal information online. Novices and veterans, however, did not differ on how they used electronic mail.

These population differences between 1995, 1998, and 2000 did not simply reflect the shifting demographics of the Internet, since controlling statistically for demographic changes did not reduce the shift towards domestication. Instead, the findings probably reflect the weaker and changed motives that people who adopt innovations late in their history typically have compared to early adopters (Rogers, 1995). It is true that different demographic groups use computing differently, with, for example, women using the Internet more than men for communication. It is also true that over the past few years, the demographics of those using personal computers and the Internet have changed, with recent Internet users becoming more like the U.S. population at large, at least in terms of gender, age and education. The changing demographics of Internet users did not, however, account for much of the shifts in use between 1995 and 1998, and between 1995 and 2000, as shown by the mediation analyses in Table 5. Indeed, in some cases, changes in the demography in the user base worked against increasing domestication. Thus, for example, even though older adults have been increasing their presence online they are less likely than younger adults to use electronic mail for personal purposes. In addition, shifts toward greater domestic and personal use were occurring within the traditional demographic groups (i.e., well educated, white males) as well within the demographic groups newly going went online.

In addition to changes in the user base, the analyses comparing identical people in 1995 and 1996 hint that changes in the Internet itself and its environment may also be driving changes toward domestic and personal uses. Even during this one-year interval, people's use of the Internet changed. In particular, in 1995 this sample was using the Internet more for work than for pleasure, but by 1996, this difference had vanished. Because we have no direct measure of how the services available or the public attitudes changed during this period, we can only speculate about mediating mechanisms. 
We see four changes in the Internet environment over the past several years that could account in part for shifts in use toward more domestic purposes. First, the growth in the number of Americans online means that people can use the Internet to keep in touch with a larger proportion of their friends and relationships than they could have several years ago when online access was more limited.

Second, new services and content make computing and the Internet increasingly attractive for personal uses. For example, the large number of entertainment sites provide opportunities for private, recreational uses that were not previously available. Similarly, the development of instant messaging services increases opportunities to keep in touch with friends and family.

Third, the increase in computing from home provides a physical environment in which personal uses are given legitimacy. At home, when surfing the Web for a hobby or sending email, one does not need to cover the screen with an ersatz spreadsheet if the boss walks in.

Fourth, to the extent that these personal changes are reflected in the news and popular media, shifts in the larger normative environment reinforce personal decisions. Consider, for example, newspaper cartoons showing Web surfers in their pajamas or the recent movie, You've Got Mail (Ephron, 1998), glorifying the email-enabled romance between business rivals. These depictions of private life in popular culture both reflect and reinforce personal uses of computers and the Internet.

The trends we observed from 1995 to 2000 are likely to continue. There are several reasons for this prediction. First, to the extent that the trends are being driven by the different motives held by early and later adopters of technology, many even later adopters remain to be brought online. Many people still feel that the benefits they could receive from home personal computers and the Internet are not worth the price it would take to overcome barriers of financial costs, technical difficulties and learning. The hold-outs include many elderly, poor, and minorities. Second, to the extent that trends are being driven partially by the physical location of computing, this shift is also likely to continue, as the number 
of American households that have computers at home continues to grow. If demand keeps rising and prices keep falling, then Internet use in the household should continue to increase. And finally, to the extent that trends are partially driven by economies of scale and by network externalities—-the lowered costs and greater benefits available later in the evolution in a technology—-these changes in the costs and benefits themselves will continue as more people go online.

\section{Limitations and Implications}

While we have shown that what people are doing online has changed from 1995 to 2000, our conclusions about the factors driving this change are neither precise nor definitive. Although we have identified behavioral differences between recent adopters and veterans, we do not know what attributes of recent adopters or the adoption processes cause the differences in online behavior.

The conclusion that changes in the Internet itself or its environment is especially speculative. We have shown that a single sample was using computing more domestically in 1996 than in 1995 . The statistical results, however, were weak, both because of a small sub-sample size and because of a short time interval. The more important problem is that the statistical results only suggest that variations in the users base between 1995 and 1996 cannot account for all of the changes in activities over this period. We, however, have no direct measures of changes to the Internet or its environment and no analyses to determine the extent to which theses changes are driving online behavior.

More predictive theory about the life cycle of innovations is needed, both to help understand historical trends in the way innovations are used over time and to help shape products and services, which will meet consumer demand and improve social welfare. Otherwise, the policy and business worlds are left with a Darwinian environment, in which entrepreneurs produce random products, some of which are selected by the then current set of potential users and most of which fail. 
Currently, the dominant market-research approach to forecasting makes the over-simplifying assumption that future behavior can be linearly extrapolated from current behavior. It was this type of analysis, done in the 1970 s and 80 s, that erroneously predicted huge increases in work-related uses of computing at home (e.g., BusinessWeek, 1984; Nilles, Carlson, Gray, \& Hanneman, 1976). Unfortunately, this approach does not take into account the changing nature of demand.

Many academic theories of change are not much better. Diffusion models predict the adoption of an innovation (e.g., Mahajan, Muller, \& Bass, 1990), but provide little guidance for understanding how the style of use shifts with an individual's experience or with the penetration of an innovation in a population. Adaptive structuration theory (DeSanctis \& Poole, 1994; Orlikowski, 2000) provides a framework for constructing post-hoc explanations of the way that use changes over time, but has weak predictive power. According to adaptive structuration theory, the material features of a technology are selectively adapted, depending upon users' expectations and the social environment in which they are placed. The technology-as-used, in turn, influences expectations and the social environment. These changed expectations and social structures feed back into the evolution or selective use of the technology, in the next cycle. Applied to the dynamics of Internet use, adaptive structuration theory suggests that over time the Internet both influenced and was influenced by the population of users and their activities online. As the Internet evolved, those who used it and what they used it for changed, which led to changes in the Internet itself, which again led to recruitment of different users and affordances for different uses.

Unfortunately, although this approach can help explain the path dependencies in the current way an innovation is used, it does not give guidance to decision makers about which of an innovation's many features will be appropriated by an audience at a particular time and how they will be used. Thus, the theory helps, in a loose way, to make sense of the changes we have been witnessing; it does not allow us 
predict what changes will take place or when those changes will occur. For example, adaptive structuration theory does not help to predict whether in the future people will use the Internet more for entertainment or other non-instrumental activities, for online shopping and other domestic chores, and for telecommuting and other work-related activities.

We believe theories emphasizing network externalities can account for the changes in Internet domestication we have observed and provide more predictive power and guidance (e.g., Katz \& Shapiro, 1994). Network externality theories describe how the value of innovations change as the numbers of users increase. In most cases, the benefit increases and costs decline with the user base. In part, these shifts in costs and benefits account for the lighter and less economically-oriented use of the Internet later in its history (Sitkin, Sutcliffe, \& Barrios-Choplin, 1992). In the case of the computing, as more people get home computers and go online, they are using the technology less heavily and for non-economical purposes. These theories can make highly differentiated predictions about the types of services or population increases will draw in particular types of uses or users (Shapiro \& Varian, 1999). For example, innovations characterized by network externality often have a winner-take-all outcome, with all potential users gravitating towards a single competitor (e.g., Kraut, Rice, Cool, \& Fish, 1998). One might expect, as a result, that a single standard for Internet instant messaging will emerge, based on American Online's Instant Messenger or ICQ products (Marsan, 2000) or that U.S. Postal mail for household-to-household communication will eventually become extinct. 
Table 1: Demographic characteristics of the three samples: 1995, 1998, and 2000.

\begin{tabular}{|l|l|l|l|l|l|l|l|}
\hline & \multicolumn{2}{|c|}{1995} & \multicolumn{2}{c|}{1998} & \multicolumn{2}{c|}{2000} & F \\
& \multicolumn{2}{|c|}{$(\mathrm{N}=4005)$} & \multicolumn{2}{c|}{$(\mathrm{N}=2000)$} & \multicolumn{2}{c|}{$(\mathrm{N}=3533)$} & \\
\hline & Mean & SD & Mean & SD & Mean & SD & \\
\hline Female & 0.51 & 0.50 & 0.53 & 0.50 & 0.53 & 0.50 & 2.14 \\
\hline Age (>35) & 0.75 & 0.43 & 0.78 & 0.41 & 0.77 & 0.42 & $5.01^{*}$ \\
\hline Education (< college) & 0.67 & 0.47 & 0.71 & 0.46 & 0.73 & 0.44 & $14.54^{* *}$ \\
\hline White & 0.84 & 0.37 & 0.83 & 0.38 & 0.80 & 0.40 & $6.51^{* *}$ \\
\hline Income (> \$40,000) & 0.45 & 0.50 & 0.46 & 0.50 & 0.49 & 0.50 & $4.00^{*}$ \\
\hline
\end{tabular}

$\dagger \mathrm{p}<.10, * \mathrm{p}<.05, * * \mathrm{p}<.01, * * * \mathrm{p}<.001$ 
Table 2: Changes in location of computing and Internet use, 1995 to 2000.

\begin{tabular}{|c|c|c|c|c|c|}
\hline & 1995 & 1998 & 2000 & $\begin{array}{l}\mathrm{T} \\
(1998-1995)\end{array}$ & $\begin{array}{l}F_{\text {linear }} \\
(2000-1995)\end{array}$ \\
\hline $\begin{array}{l}\text { Do you, yourself, ever use a computer at home, } \\
\text { at work, or at school (\% yes) }\end{array}$ & $66 \%$ & $67 \%$ & & .84 & \\
\hline$\%$ at work & $74 \%$ & $66 \%$ & & $-4.69 * * *$ & \\
\hline$\%$ at home & $66 \%$ & $69 \%$ & & 1.45 & \\
\hline $\begin{array}{l}\text { Frequency of use (days per month, for those who } \\
\text { ever use a computer at home) }\end{array}$ & 8.79 & 10.73 & & $5.19 * * *$ & \\
\hline $\begin{array}{l}\text { Did you happen to use a personal computer at } \\
\text { home yesterday (\% yes) }\end{array}$ & $18 \%$ & $20 \%$ & & $2.14 *$ & \\
\hline $\begin{array}{l}\text { About how much time did you spend using a } \\
\text { personal computer at home yesterday (minutes } \\
\text { per day, for those who used it at all.) }\end{array}$ & 93.11 & 83.96 & & $-2.04 *$ & \\
\hline Did you happen to go online yesterday? (\% yes) & $8 \%$ & $18 \%$ & $29 \%$ & & $575.3^{* * *}$ \\
\hline$\%$ online from work & $48 \%$ & $28 \%$ & $41 \%$ & & 2.54 \\
\hline$\%$ online from home & $71 \%$ & $76 \%$ & $76 \%$ & & $5.17 *$ \\
\hline $\mathrm{N}$ & 4005 & 2000 & 3533 & & \\
\hline
\end{tabular}

$\dagger \mathrm{p}<.10, * \mathrm{p}<.05, * * \mathrm{p}<.01, * * * \mathrm{p}<.001$ 
Table 3: Changes in the reasons for computing and Internet use, 1995 to 2000.

\begin{tabular}{|c|c|c|c|c|c|}
\hline & 1995 & 1998 & 2000 & $\begin{array}{l}\mathrm{t} \\
(1998-1995)\end{array}$ & $\begin{array}{l}\mathrm{F}_{\text {linear }} \\
(2000-1995)\end{array}$ \\
\hline $\begin{array}{l}\text { Do you use your home computer in } \\
\text { connection with your job, for school, for } \\
\text { personal use, or some combination of these? }\end{array}$ & & & & & \\
\hline Job (\% yes) & $62 \%$ & $49 \%$ & & $-6.33 * * *$ & \\
\hline Personal (\% yes) & $91 \%$ & $86 \%$ & & $-3.68 * * *$ & \\
\hline $\begin{array}{l}\text { Some people go online for work-related } \\
\text { activities, some do it for pleasure, and for } \\
\text { others it's some of each. How about you... } \\
\text { all work, all pleasure, or a mix? }\end{array}$ & & & & & \\
\hline Work (\% yes for work or both) & $81 \%$ & $73 \%$ & & $-4.05 * * *$ & \\
\hline Pleasure (\% yes for pleasure or both) & $68 \%$ & $87 \%$ & & $9.48 * * *$ & \\
\hline $\begin{array}{l}\text { Please tell me how often, if ever, you } \\
\text { engage in each of the following online } \\
\text { activities. First, how often do you go online } \\
\text { to (days per month) }\end{array}$ & & & & & \\
\hline $\begin{array}{l}\text { Get financial information such as } \\
\text { stock quotes or corporate } \\
\text { information or to buy stocks or } \\
\text { bonds }\end{array}$ & 2.26 & 5.43 & & $8.48 * * *$ & \\
\hline Get news and information on current & 4.90 & 6.37 & & $3.56 * * *$ & \\
\hline
\end{tabular}




\begin{tabular}{|c|c|c|c|c|c|}
\hline events, public issues or politic & & & & & \\
\hline $\begin{array}{l}\text { Get travel or vacation } \\
\text { information or services }\end{array}$ & .76 & 2.24 & & $7.40 * * *$ & \\
\hline $\begin{array}{l}\text { Get information about hobbies, } \\
\text { movies, restaurants or other } \\
\text { entertainment-related activities }\end{array}$ & 2.31 & 4.93 & & $8.94 * * *$ & \\
\hline $\begin{array}{l}\text { Do you communicate with any friends or } \\
\text { family members by email? (\% yes) }\end{array}$ & $42 \%$ & $68 \%$ & $82 \%$ & & $540.3 * * *$ \\
\hline $\begin{array}{l}\text { Is your use of email work-related, personal } \\
\text { or both? }\end{array}$ & & & & & \\
\hline Work (\% yes) & $51 \%$ & $52 \%$ & $51 \%$ & & .054 \\
\hline Personal (\% yes) & $50 \%$ & $73 \%$ & $82 \%$ & & $329.5 * * *$ \\
\hline $\mathrm{N}$ & 4005 & 2000 & 3533 & & \\
\hline
\end{tabular}

$\dagger \mathrm{p}<.10, * \mathrm{p}<.05, * * \mathrm{p}<.01, * * * \mathrm{p}<.001$ 
Table 4: Temporal differences in domestication controlling for demographic shifts in the user base,

$\underline{1995-2000 .}$

\begin{tabular}{|c|c|c|c|c|c|c|c|c|c|c|c|c|}
\hline $\begin{array}{l}\text { (Model) } \\
\text { Independent } \\
\text { variable }\end{array}$ & \multicolumn{3}{|c|}{$\begin{array}{l}\text { (1) Going online } \\
\text { yesterday from } \\
\text { home - work }\end{array}$} & \multicolumn{3}{|c|}{$\begin{array}{l}\text { (2) Using home } \\
\text { computer for } \\
\text { personal - work }\end{array}$} & \multicolumn{3}{|c|}{$\begin{array}{l}\text { (3) Going online } \\
\text { for pleasure - work }\end{array}$} & \multicolumn{3}{|c|}{$\begin{array}{l}\text { (4) Using email for } \\
\text { personal - work }\end{array}$} \\
\hline & Beta & $\mathrm{T}$ & $\mathrm{p}$ & Beta & $\mathrm{T}$ & $\mathrm{p}$ & Beta & $\mathrm{t}$ & $\mathrm{p}$ & Beta & $\mathrm{t}$ & $\mathrm{p}$ \\
\hline Female & -.07 & -2.92 & $* *$ & .06 & 2.75 & $* *$ & -.08 & -3.13 & $* *$ & .02 & 1.31 & \\
\hline Age $(>35)$ & -.04 & -2.03 & $*$ & -.02 & -0.88 & & -.06 & -2.24 & $*$ & -.10 & -5.24 & $* * *$ \\
\hline $\begin{array}{l}\text { Education } \\
(<\text { college })\end{array}$ & -.01 & -.008 & & .12 & 5.43 & $* * *$ & .02 & .72 & & .10 & 5.62 & $* * *$ \\
\hline White & .05 & 2.47 & $*$ & .03 & 1.36 & & .10 & 3.96 & $* * *$ & .09 & 5.12 & $* * *$ \\
\hline $\begin{array}{l}\text { Income } \\
(>\$ 40,000)\end{array}$ & -.01 & -.467 & & -.08 & -3.57 & $* * *$ & .02 & .67 & & -.05 & -2.74 & $* *$ \\
\hline $\begin{array}{l}\text { Time } \\
(2000,1998,1995)\end{array}$ & .14 & 3.08 & $* * *$ & .05 & 2.36 & $*$ & .20 & 7.78 & $* * *$ & .19 & 10.6 & $* * *$ \\
\hline $\mathrm{N}$ & 2228 & & & 2228 & & & 1481 & & & 2869 & & \\
\hline $\mathrm{R}-\mathrm{Sq}$. & .03 & & & .03 & & & .06 & & & .08 & & \\
\hline
\end{tabular}

$\dagger \mathrm{p}<.10, * \mathrm{p}<.05, * * \mathrm{p}<.01, * * * \mathrm{p}<.001$

Note. t-tests for Time represent an interaction. Increases in domestication from 1995 to 1998 in the case of going online yesterday from home-work (model 1) and going online for pleasure-work (model 3), and increases in domestication from 1995 to 2000 in the case of using home computer for personal-work (model 2) and using email for personal-work (model 4). 
Table 5: Uses of computing and the Internet by veterans and novices in 1998 and 2000.

\begin{tabular}{|l|l|l|l|l|l|l|}
\hline & \multicolumn{3}{|c|}{1998} & \multicolumn{3}{c|}{2000} \\
\hline & Veteran & Novice & $\mathrm{t}_{\text {(novice-veteran) }}$ & Veteran & Novice & $\mathrm{t}_{\text {(novice-veteran) }}$ \\
\hline$\%$ Female & $45 \%$ & $53 \%$ & $2.30 *$ & $46 \%$ & $54 \%$ & $3.08 *$ \\
\hline$\%>30$ years old & $67 \%$ & $74 \%$ & $2.18 *$ & $67 \%$ & $71 \%$ & $1.82 \dagger$ \\
\hline$\%$ White & $44 \%$ & $64 \%$ & $5.69 * * *$ & $52 \%$ & $73 \%$ & $8.72 * * *$ \\
\hline$\%$ income $>\$ 40,000$ & $88 \%$ & $86 \%$ & -.88 & $84 \%$ & $81 \%$ & -1.49 \\
\hline Use a computer from work & $62 \%$ & $58 \%$ & -1.17 & $68 \%$ & $58 \%$ & $-3.85 * * *$ \\
\hline Use a computer from home & $75 \%$ & $71 \%$ & -1.31 & & & \\
\hline Use home computer for work & $87 \%$ & $78 \%$ & $-3.20 * *$ & & & \\
\hline Use home computer for personal & $59 \%$ & $46 \%$ & $-3.02 * *$ & & & \\
\hline Use the Internet from work yesterday & $87 \%$ & $86 \%$ & -.29 & & & \\
\hline Use the Internet from home yesterday & $74 \%$ & $79 \%$ & 1.00 & $75 \%$ & $78 \%$ & .97 \\
\hline Use the Internet for work & $81 \%$ & $64 \%$ & $-5.35 * * *$ & & & \\
\hline Use the Internet for pleasure & $89 \%$ & $84 \%$ & $-2.15 *$ & & & \\
\hline Use email for work reasons & $62 \%$ & $40 \%$ & $-6.35 * * *$ & $58 \%$ & $38 \%$ & $-8.18 * * *$ \\
\hline Use email for personal reasons & $83 \%$ & $62 \%$ & $-7.00 * * *$ & $85 \%$ & $76 \%$ & $-4.79 * * *$ \\
\hline $\mathrm{N}$ & 431 & 353 & & 1050 & 635 & \\
\hline
\end{tabular}

$\dagger \mathrm{p}<.10, * \mathrm{p}<.05, * * \mathrm{p}<.01, * * * \mathrm{p}<.001$ 
Table 6: Informational uses of the Internet by veterans and novices in 1998.

\begin{tabular}{|c|c|c|c|c|}
\hline & $\begin{array}{l}\text { Veteran } \\
\text { (means days } \\
\text { per month) }\end{array}$ & $\begin{array}{l}\text { Novice } \\
\text { (means days } \\
\text { per month) }\end{array}$ & $\mathrm{t}_{\text {(novice-veteran) }}$ & $\mathrm{p}$ \\
\hline \multicolumn{5}{|l|}{ Work-related information } \\
\hline Look for information for work or job & 11.06 & 5.95 & -4.96 & $* * *$ \\
\hline \multicolumn{5}{|l|}{ Personal and family related information } \\
\hline $\begin{array}{l}\text { Get financial information such as stock } \\
\text { quotes }\end{array}$ & 6.40 & 4.21 & -3.25 & $* *$ \\
\hline $\begin{array}{l}\text { Get news and information on current } \\
\text { events, public issues or politics }\end{array}$ & 7.50 & 5.04 & -3.74 & $* * *$ \\
\hline $\begin{array}{l}\text { Get travel or vacation } \\
\text { Information or services }\end{array}$ & 2.24 & 2.20 & -.09 & \\
\hline $\begin{array}{l}\text { Get information about hobbies, movies, } \\
\text { restaurants or other entertainment- } \\
\text { related activities }\end{array}$ & 5.46 & 4.34 & -2.07 & $*$ \\
\hline Pay bills or bank online & 1.39 & 1.18 & -.41 & \\
\hline Get health or medical information & 2.47 & 1.86 & -1.72 & $\dagger$ \\
\hline $\mathrm{N}$ & 431 & 353 & & \\
\hline
\end{tabular}

$\dagger \mathrm{p}<.10, * \mathrm{p}<.05, * * \mathrm{p}<.01, * * * \mathrm{p}<.001$ 
Table 7: Shifts in domestication within individuals, 1995 to 1996

\begin{tabular}{|c|c|c|c|c|}
\hline & 1995 & 1996 & $\mathrm{t}_{(1996-1995)}$ & $\mathrm{p}$ \\
\hline $\begin{array}{l}\text { Use a computer from home (of those who used a } \\
\text { computer at all) }\end{array}$ & $87 \%$ & $87 \%$ & .00 & \\
\hline $\begin{array}{l}\text { Use a computer from work (of those who used a } \\
\text { computer at all) }\end{array}$ & $84 \%$ & $85 \%$ & .42 & \\
\hline $\begin{array}{l}\text { Used the Internet from home yesterday (of those } \\
\text { who used the Internet at all) }\end{array}$ & $66 \%$ & $71 \%$ & .66 & \\
\hline $\begin{array}{l}\text { Used the Internet from work yesterday (of those } \\
\text { who used the Internet at all) }\end{array}$ & $54 \%$ & $46 \%$ & -.97 & \\
\hline $\begin{array}{l}\text { Use the Internet for pleasure (of those who used } \\
\text { the Internet at all) }\end{array}$ & $68 \%$ & $81 \%$ & 3.07 & $* *$ \\
\hline $\begin{array}{l}\text { Use the Internet for work (of those who used the } \\
\text { Internet at all) }\end{array}$ & $81 \%$ & $85 \%$ & 1.08 & \\
\hline $\mathrm{N}$ & 194 & 194 & & \\
\hline
\end{tabular}

$\dagger \mathrm{p}<.10, * \mathrm{p}<.05, * * \mathrm{p}<.01, * * * \mathrm{p}<.001$ 


\section{References}

Anderson, R., Bikson, T., Law, A., \& Mitchell, B. 1995. Universal access to Email. Santa Monica, CA: RAND.

Aronson, S. 1977. Bell's electrical toy: What's the use? The sociology of early telephone usage. In de Sola Pool, I. (Ed). The Social Impact of the Telephone. Cambridge, Massachusetts: MIT Press.

Bernard, H., Killworth, P., \& Sailor, L. 1980. Informant accuracy in social network data IV: A comparison of clique-level structure in behavioral and cognitive data. Social Networks, 2, 191-218.

BusinessWeek. 1984. It's rush hour for 'telecommuting'. January 23.

Clemente, P. 1998. The state of the Net. New York: McGraw-Hill.

DeSanctis, G., \& Poole, M. 1994. Capturing the complexity in advanced technology use: Adaptive structuration theory. Organization Science 5(2):121-147.

Ephron, N. 1998. You've got mail. Hollywood, CA: Warner Brothers.

Freeman, L., Romney, A., \& Freeman, S. 1987. Cognitive structure and informant accuracy. American Anthropologist, 89, 310-325.

Frenkel, K. 1990. Women and computing. Communications of the ACM 33(11): 34-46.

Hoffman, D., Kalsbeek, W. \& Novak, T. (1996). Internet and Web use in the U.S. Communications of the ACM. 39(12), 36-46

Hoffman, D., \& Novak, T. 1997. Bridging the racial divide on the Internet. Science 280: 390-391.

Katz, M. \& Shapiro, C. 1994. Systems competition and network effects. Journal of Economic Perspectives 8(2): 93-115

Klawe, M., \& Leveson, N. 1995. Women in computers: Where are we now? Communications of the ACM 38(1): 29-35.

Kraut, R. 1989. Telecommuting: The tradeoffs of home work. Journal of Communication 39(3): 19-47.

Kraut, R. 1996. The Internet at home. Communications of the ACM 39(12): 32-63.

Kraut, R., Rice, R., Cool, C. \& Fish, R. 1998. Varieties of social influence: The role of utility and norms in the success of a communication medium. Organizational Science 9(4): 437-453.

Mahajan, V., Muller, E., \& Bass, F. 1990. New product diffusion models in marketing: A review and directions for research. Journal of Marketing 54: 1-26.

Marsan, C. (2000, May 5). Pressure mounts for instant messaging standard. CNN. Downloaded May 4, 2001 from http://www.cnn.com/2000/TECH/computing/05/02/icu.standard.idg/.

Nilles, J., Carlson, F. R., Gray, P., \& Hanneman, G. 1976. Telecommunications/transportation tradeoffs: Options for tomorrow. New York: Wiley.

Orlikowski, Wanda (2000). Using technology and constituting structures: A practice lens for studying technolgy in organizations. Organizational Science, 11(4), 404-428.

Pew Internet and American Life Project. 2001. http://www.pewinternet.org

Rogers, E. (1995). The diffusion of innovations. New York: Free Press. 
Shapiro, C. \& Varian, H. 1999. Information Rules. Cambridge MA: Harvard University Press.

Silverstone, R. \& Haddon, L. 1996. Design and the domestication of information and communication technologies: Technical change and everyday life. In R. Mansell \& R. Silverstone (Eds.), Communication by design: The politics of information and communication technologies (pp. 44-74). New York: Oxford University Press.

Sitkin, S., Sutcliffe, K., \& Barrios-Choplin, J. 1992. A dual-capacity model of communication media choice in organizations. Human Communication Research 18(4): 563-598.

Stone A. A., Turkkan, J. S. Cachrach, C. A. Jobe, J. B. Kurtzman, H. S. \& Cain V. S. (Eds.), (2000). The science of self-report: Implications for research and practice. Mahwah, NJ: Erlbaum.

Times Mirror Center for the People and the Press. 1994. Technology in the American household. Los Angeles: Times Mirror.

U.S. Department of Commerce. 1999. Falling through the Net: Defining the digital divide. Washington, DC: U.S. Department of Commerce.

Vitalari, N., Venkatesh, A., \& Gronhaug, K. 1985. Computing in the home: Shifts in the time allocation patterns of households. Communications of the ACM 28(5): 512-522.

\footnotetext{
${ }^{\mathrm{i}}$ Response rates were 54\%, 47\% and 40\% respectively for the 1995, 1998, and 2000 surveys.
}

These differences in response rates are a cause for some concern. To examine more deeply the question of whether the samples are equivalent, Table 1 compares the three samples on their distribution of demographic characteristics. There are significant differences among the three samples, since Current Populations Statistics do not show similar changes in the distribution of the U.S. population during these periods. This suggests that the differences are due to a non-response bias. Some authors recommend controlling for nonrespondent bias by adjusting samples to the demographic rates revealed by the Current Populations Survey (Hoffman, Kalsbeek, \& Novak, 1996). This is an inappropriate producedure, however, for two reasons. First, it makes it makes the implausible assumption that members of a demographic group who fail to complete a survey are a random sample of the population as a whole and are thus similar to those who complete it. Second, it assumes that statistically adjusting for demographic characteristics also adjusts appropriately for all other attributes of interest. Instead of adjusting for the demography of the sample, we will treat the non-responses as an alternative explanation for possible differences we identify across time. 
